\title{
Applications of laser ablation and electrothermal vaporization as sample introduction techniques for ICP-MS
}

\author{
Peter Richner', Douglas Evans ${ }^{1 * *}$, Christoph Wahrenberger'2, Volker Dietrich ${ }^{2}$

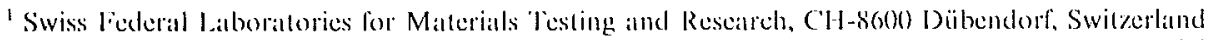 \\ ${ }^{2}$ Institule for Mincralogy and Petrogeraphy, Swiss lederal Instilute of Techarology, CH-8092 Zürich, Switzerland
}

Reccived: 28 December 1993 / Accepted: 7 April 1994

\begin{abstract}
The field of applications of ICP-MS can be further increased by the usc of special sample introduction techniques such as laser ablation (LA) and electrothermal vaporization (ETV). In both calses a tandem source for mass spectrometry is formed by the sample introduction device and the ICP. The first source is specifically designed for the volatilization of a sample and it cain be used to introduce selectively only certain parts of a sample into the ICP-MS, based either on local distribution (LA) or volatility (ETV). Applications of LA-ICP-MS alre the determination of distribution patterns of minor constituents in solid samples such as ceramics, alloys or hard biological structures. Homogeneity testing in the first two types of samples or determination of distribution patterns of trace clements in the latter can be carried out rapidly with high spatial resolution on a multiclement basis. The possibility of on-line separation between fractions of different volatility in a sample with ETV-ICP-MS is demonstrated for volcanic eruption products and other samples.
\end{abstract}

\section{Introduction}

Inductively coupled plasma mass spectrometry (ICP-MS) is applied routinely in many difierent fields such as material science, environmental protection, quality control and many more becaluse of the wide range of elements covered, the low detection limits, the high sample throughput and the reliability of modern instruments in day to day operation. Much of the research and development work is directed lowards betler sensitivity and resolution, but sample introduction must also receive attention. The majority of analyses by ICP-MS are carried out on solutions using a conventional pneumatic nebulizer. However the type of analytical tasks which can be solved by ICP-MS can be extended using a number of other sample introduc-

*Permanent address: Trent University, Peterborough, Ontario, Canalda, K9J $7 \mathrm{~B} 8$

Correspondence to: P. Richner tion techniques which can be easily adapted to ICP-MS, such as flow injection (FI), liquid chromatography (LC), laser ablation (LA) and electrothermal vaporization (ETV). These introduction techniques cither help to overcome some of the limitations posed by the pneumatic nebulizers (i.c. lotal amount of dissolved solid has to be less than $0.1 \% \mathrm{~m} / \mathrm{v}$ ) or they make use of some physical properties of the sample which in turn enhances the analytical information gained during the analysis.

The reactions produced upon the interaction of laser light with a solid sample have been used for al long time for analytical purposes $[1,2]$. Among the methods developed are laser microprobe optical emission spectrometry and laser microprobe mass spectrometry. The ability to focus a laser to very small spot sizes and therefore to achicve analytical results with high spatial resolution was one of the driving forees for the development of the methods, logether with the fact that they can be applied to both conducting and non-conducting materials. The same is true for the use of laser ablation as a sample introduction technique for ICP-MS, where it provides one of the lew possibilities to analyze solid samples directly by ICPMS. Unfortunately the method suffers from some serious drawbacks when it comes to quantitative analysis. The ablation process is highly dependent on the nature of the sample and direct calibration is only possible when standard materials are available with a matrix similar to the sample. In such an ideal case, an accuracy of 5 to $10 \%$ is possible but in many other cases the method has to be considered as semiquantitative. The real strength of $\mathrm{LA}$ lies in the measurement of distribution patterns of trace elements in solid samples with high spatial resolution $[3,4]$. In these cases, often only relative numbers are needed and, by using one or more of the matrix elements as internal standards, a precision of better than $10 \%$ is possible.

Filaments, platforms or tubes of high temperature resistant materials, such as tungsten or graphite, can be used as ETV devices. Several $\mu$ lof solution are deposited on the surface and the temperature is controlled by an electrical current flowing through the device. The most common devices ate graphite furnaces similar to those used in GF-AAS. The most important advantages of ETV 
compared to conventional solution nebulization are the low sample consumption $(<100 \mu l)$, the higher transport efficiency and a lower level of $\mathrm{MO}^{+}$ions formed when aqueous solutions are analyzed. A severe drawback of the method is the relatively short transient signal of $1-2 \mathrm{~s}$ produced by the ETV. Only a relative small number of elements can be analyzed per cycle because the quadrupole mass spectrometer is a sequential ather than a simultaneous detector. Typical applications are the analysis of high purity reagents and the determination of $\mathrm{Fe}$ with a much lower detection limit because of the reduction of the interference from ${ }^{40} \mathrm{Ar}^{16} \mathrm{O}^{+}$with ${ }^{56} \mathrm{Fe}$ [5].

This paper shows how sample introduction techniques such as LA and ETV can be used in routine analysis in a laboratory which is dedicated both to contract work for industrial customers and research activities in cooperation with other academic research groups. Among the examples selected are the determination of distribution patterns of trace metals in hard biological structures and homogeneity testing on low alloy steel samples by LAICP-MS. ETV-ICP-MS has been used for the analysis of $\mathrm{Hg}$ in $\mathrm{AgNO}_{3}$ at the low $\mathrm{ng} / \mathrm{g}$ level and the determination of volatile compounds in products from volcanic eruptions.

\section{Experimental}

The work described was carried out using an Elan 5000 instrument in combination with a Model 320 Laser Sampler for the laser ablation experiments and a HGA600MS for the ETV experiments (Perkin-Elmer Sciex, Thornhill, Ontario, Canada). The ICP-MS was optimized daily by adjusting the power (1000 W to $1200 \mathrm{~W}$ ) and the nebulizer gas flow $(0.8 \mathrm{l} / \mathrm{min}$ to $1.0 \mathrm{l} / \mathrm{min})$. Plasma and auxiliary flows were kept constant at $15 \mathrm{l} / \mathrm{min}$ and 0.8 $\mathrm{l} / \mathrm{min}$, respectively. The laser ablation unit included a $\mathrm{Nd}$ : YAG laser, a sample stage with three computer controlled stepper motors and a video camera system for the observation of the sample. The unit was modified in various ways in order to have a more flexible and user friendly system [6]. Among the hardware modifications are a new sampling cell which allows the illumination of the sample from the top, the side and the bottom and an additional laser diode which helps to locate points of interest on the sample. Flat samples can be clamped against a ring which is perpendicular to the laser beam so that focusing is maintained throughout the analysis. In order to achicve the degree of automation needed for the determination of distribution patterns (which usually includes the analysis of hundreds of points per sample) a computer program was written controlling the laser, the sample stage and the ICP-MS. A focusing lens with a focal length of $40 \mathrm{~mm}$ was used throughout the work. The ETV device is based on a conventional graphite furnace for atomic absorption spectrometry (GF-AAS) with slightly different gas flows. The carrier gas stream is directed through the graphite tube during the vaporization step and the sample introduction hole is sealed with a graphite tip so that efficient transport of the analyte from the graphite furnace into the ICP is guaranteed. Pyrocoated tubes were used throughout the work (Perkin-Elmer, Norwalk, CT, USA).
LA-ICP-MS analysis was carried out using the low alloy steel standard reference materials NBS $1161-N B S$ 1168 (National Bureau of Standards, Gaithersburg, MD 20899, USA). For the quantitative work the laser was focused to a spot sizc of approximately $2 \mathrm{~mm}$. The laser was fired at $10 \mathrm{~Hz}$ and data aceuisition was started alter a preablation of $30 \mathrm{~s}$. For the homogeneity testing, the laser was focused to $50 \mu \mathrm{m}$ and 10 shots at $2 \mathrm{~Hz}$ per point were applied. Sections of teeth and fin ray samples were prepared with a thickness of approximately $0.5 \mathrm{~mm}$. This allows light transmission through the samples and therefore makes the annual lines visible on the screen. Prior to analysis, samples were washed in 10\% nitric acid for a few seconds and rinsed in distilled water.

The nitric acid used in this work was re-distilled in quartz from pro analysi grade nitric acid (E. Merck, Darmstadt, Germany); de-ionized water from a Milli Q Plus system (Millipore Corp., Bedford, MA, USA) was used with an indicated outlet conductivity of $18 \mathrm{M} \Omega^{-1}$. Mercury standard solutions were prepared from a $1000 \mu \mathrm{g} / \mathrm{l}$ stock solution (E. Merck, Darmstadt, Germany). All vessels were cleaned overnight prior to their use with $10 \%$ $\mathrm{m} / \mathrm{m}$ nitric acid.

\section{Results and discussion}

Why are sample introduction techniques such as LA, ETV or LC in combination with ICP-MS so successfult? The key word for all these systems is tandem source mass spectrometry [7]. Instead of one source being responsible for the vaporization, atomization and ionization of the sample, these tasks can be divided among two different sources as shown in Fig. 1. In the case of LA and ETVICP-MS, the first source is mainly responsible for the vaporization of the sample and the ICP for the atomization and ionization steps. Finally, the mass spectrometer is used for identification and quantification of the analytes. The addition of a separate source for the volatilization step provides the analytical chemist with more control over this process; this in turn means that more analytical information can be gained from the analysis. In the casc of LA local analysis can be carried out by selectively ablating material from small areas on a solid sample. This spatial information is lost when the solid sample is digested prior to the analysis. An ETV

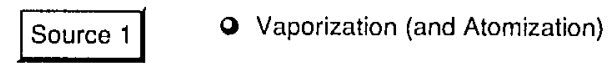

Source 2 (Atomization and) Ionization

Mass Spectrometer - Identification and Quantification

Fig. 1. The concept of Tandem Sonted Mass Spectrometry 
device can be used to separate volatile components from refractory components of a sample using an appropriate temperature program. Typical examples of how tandem sources, such as LA-ICP and ETV-ICP, can be used to solve analytical problems are given below.

\section{Laser ablation ICP-MS}

The most severe problem with LA is the high dependence of the ablation rate upon the type of material. This makes quantilative analysis difficult in the absence of maltrixmalched standards, a case frequently encountered in routine analysis. However quantitative analysis by LA-ICPMS is possible if appropriate standards are available. A typical example is the analysis of low alloy steel where the matrix of the sample is well known. In Table l, some results for the analysis of standard reference materials alre shown using ${ }^{57} \mathrm{Fe}$ as an internal standard. Similar results can be achieved by spark emission measurements. Standard addition calibration and external calibration can be applied to the analysis of powdered samples which can be pressed into pellets but the technique is time consuming because of the homogenization step involved [8]. In the absence of standards, semiquantitalive results can be produeed with a relative precision of between 30 and $80 \%$; this is in many cases still sufficient especially if the inhomogeneity of environmental samples such as soils is considered [9].

The unique strength of LA lies in the determination of distribution patterns of minor and trace elements in solid samples with high spatial resolution. For this type of analysis relative rather than quantitative numbers are needed and therefore no standards are required. The method offers a spatial resolution of $51050 \mu \mathrm{m}$ (depending on the wavelength of the laser) and multielement analysis with detection limits at the sub $\mu \mathrm{g} / \mathrm{g}$ level for conducting and non-conducting matcrials can be performed. However, in order to measure distribution patterns on a routine basis, a high degree of automation is required since hundreds of points must often be analyzed to fully characterize a sample. A software program has been developed which permits the automated analysis of up to 500 points; all of the laser parameters (lascr energy, pulse mode, spot size, requency and number of the laser shots per spot) can be specified for each single point [6]. Two typical applications are the determination of trace metals in hard biological structures and homogeneity testing of alloys and ceramics.

There are many biological structures which accumulate or grow incrementally over the life span of an organism. If materials deposited in those structures are not subject to migration or chemical breakdown, the tissue will retain a historical record of exposure to a variety of substances. Structures which have the potential to be used in this fashion include fin rays from fish, shells of marine and freshwater bivalves, tree cores and teeth from a valriety of mammals. An additional benefit of these hard structures over soft tissues is that they are not affected by bacterial breakdown over long periods of time. Samples which have been preserved for decades or centuries can increase greally the historical record available. However this wealth of historical information on environmental change can be easily obtained only via solid sampling techniques such as LA-ICP-MS. The analysis of a fin ray from a sturgeon which was more than one hundred years old when it was captured in Canada can serve as an example of the potential of the method. The animal lived in an areal where a lot of mining commenced during the life span of the fish and the goal of the experiment was to find the traces of these anthropogenic activities in the fin ray. More than 100 points were analyzed on the cross section of the fin ray with a spatial resolution of approximately $50 \mu \mathrm{m} .20$ shots in the Q-Switch mode were fired at a frequency of $1.5 \mathrm{~Hz}$ on each spot. While firing the laser at higher frequencies produces a more stable signal, lower frequencies should be used with hard biological structures, which tend to form cracks when the laser is firing at $10 \mathrm{~Hz}$; this is most probably because they cannot dissipate the heat deposited in the sample last enough. A typical signal for one spot is shown in Fig. 2. A total number of 8 elements was measured from which only 3 are shown: ${ }^{44} \mathrm{Cal}$ which was used as an internal standard, ${ }^{107} \mathrm{Ag}$ and ${ }^{202} \mathrm{Hg}$. Since the laser was moved perpendicularly to the annual lines, temporal changes in the contents of trace metals can be measured as is shown in Fig. 3 for $\mathrm{Ag}$. The concentration of $\mathrm{Ag}$ in the fin ray increased between 1900 and 1950 by two orders of magnitude which coincides with the quantity of the silver mining activity in this areal. Similar measurements have been carried out analyzing teeth from walruses and beluga whales from the Canadian aretic. Despite the fact that these animals live remote from any anthropogenic source of heavy metals such as $\mathrm{Cd}$ and $\mathrm{Pb}$, contents of these elements in soft

Table 1. Results for the analysis of a low alloy stecl standard relerence malerial (NBS 1162) by LA-ICP-MS using NBS 1161, 1163, 1164, 1165, 1166, 1167 and 1168 as external standards and ${ }^{57}$ Fe is an internal standard. All concentrations alre given in $\mu \mathrm{g} / \mathrm{g}$. Operating conditions: ICP-MS: $1100 \mathrm{~W}$, nebulizer gass llow $1 \mathrm{l} / \mathrm{min}$, dwell time $50 \mathrm{~ms}, 100$ replicates; Lalser: Q-Switch Mode, laser energy $95 \mathrm{~mJ}$, laser repetition rate $10 \mathrm{~Hz}$, spot size diameter $2 \mathrm{~mm}$

\begin{tabular}{lcccc}
\hline Element & Cert. value & $\begin{array}{c}\text { LA-ICP-MS } \\
\pm \operatorname{sid} \text { dev. }(n=3)\end{array}$ & Regression coefricient \\
\hline $\mathrm{V}$ & 580 & $598 \pm 75$ & 0.9972 & $20-1700$ \\
$\mathrm{Cr}$ & 7400 & $7580 \pm 615$ & 0.9980 & $40-7400$ \\
$\mathrm{Co}$ & 1100 & $1135 \pm 45$ & 0.9992 & $80-2600$ \\
$\mathrm{Cu}$ & 2000 & $1850 \pm 159$ & 0.9914 & $190-3400$ \\
$\mathrm{Mo}$ & 800 & $775 \pm 59$ & 0.9935 & $50-3000$ \\
\hline
\end{tabular}


tissues such as kidney are very high. Levels of up to $100 \mu \mathrm{g} / \mathrm{g}$ of $\mathrm{Cd}$ are not uncommon [10]. In order to clarify whether these elements have been accumulated over a long period of time through the food chain or whether the problem is related to anthropogenic activities, teeth from different time periods starting one or two hundred years ago up to the present should be analyzed. So far only preliminary results can be presented. Among the most interesting are distribution patterns of $\mathrm{Pb}$ in a walrus tooth, as shown in Fig. 4. The highest $\mathrm{Pb}$ concentral-

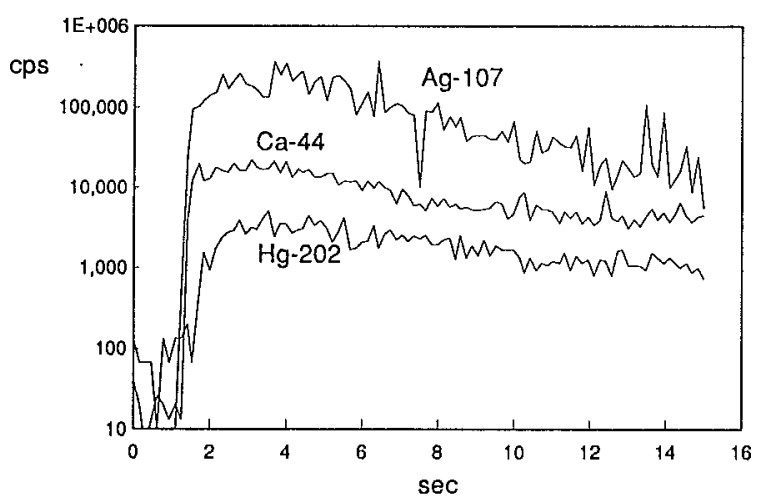

Fig. 2. Analysis of a fin ray from a sturgeon with LA-ICP-MS. Operalting conditions: ICP-MS: power $1000 \mathrm{~W}$, nebulizer gas flow $1.0 \mathrm{l} / \mathrm{min}$ dwell time $20 \mathrm{~ms}$; Laser: Q-Switch Mode, laser energy $70 \mathrm{~mJ}$, lasel repetition rate $1.5 \mathrm{~Hz}$, spot size diameter approximalely 50 fm, 20 pulses

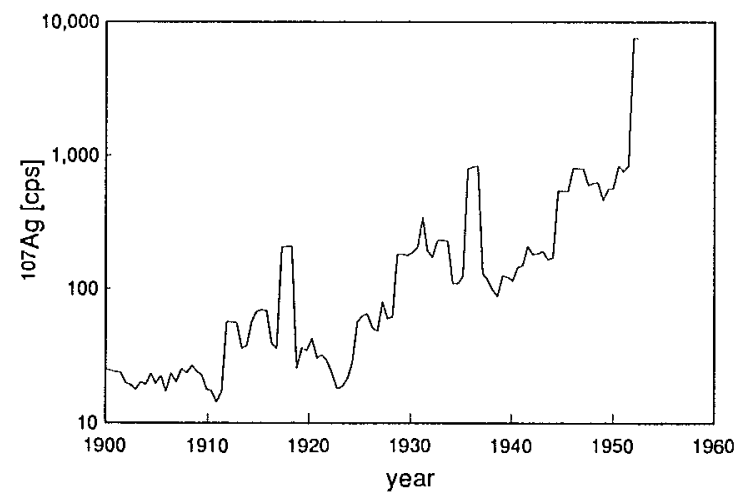

Fig. 3. Changes in the intensity of signal of ${ }^{107} \mathrm{Ag}$ in a lin ray from a sturgeon between 1900 and 1950. Experimental conditions as in Fig. 2 tions are always found in the oldest part of the tooth which means that the animal takes up much more $\mathrm{Pb}$ in its infancy. Probably this is related to the breast feeding in this period; the milk is the source of the $\mathrm{Pb}$. The $\mathrm{Pb}$ concentration drops dramatically later in life when the nutritional behaviour ehanges. These two examples illustrate how valuable LA-ICP-MS can be for the determination of distribution patterns of multielement traces in hard biological structures.

Homogeneity testing is another possible application for LA-ICP-MS. In order to validate the method, a low alloy steel sample (NBS 1 162) was analyzed for 6 elements using ${ }^{57} \mathrm{Fe}$ as an internal standard. The ratio of $\operatorname{cps}($ analyte $) / \operatorname{cps}\left({ }^{57} \mathrm{Fe}\right)$ can be used to visualize the degree of the homogeneity of the distribution of the analyte clement. The laser was focused to a spot size of $50 \mu \mathrm{m}$ and 10 shots at $2 \mathrm{~Hz}$ were fired per site in the Q-Switch mode analyzing 100 points separated by $0.5 \mathrm{~mm}$ from each other on an area of $5 \mathrm{~mm}$ by $5 \mathrm{~mm}$. All elements had to be measured with reduced sensitivity in order to prevent saturation of the detector and since this reduction was different for cach clement the ratios of the intensities given in Figs. 5 and 6 are not directly related to the ratios of the concentrations. Elements which are soluble in iron, such as $\mathrm{Cr}, \mathrm{Co}$ or $\mathrm{Ni}$, are homogeneously distributed as the surface plot for $\mathrm{Ni}$ in Fig. 5 shows. The relative standard

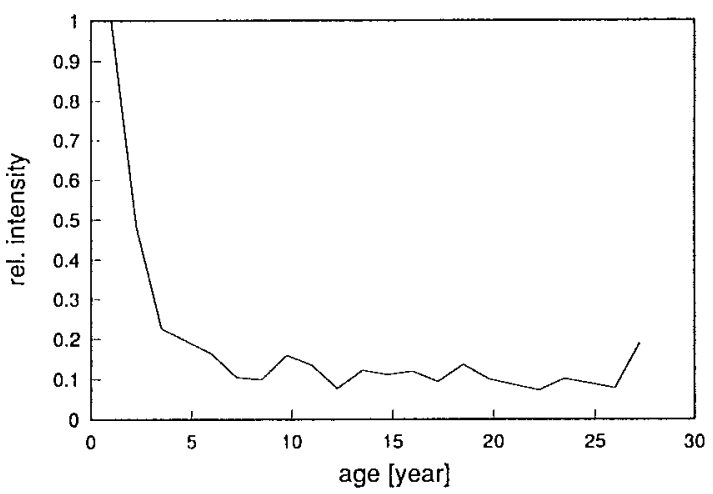

Fig. 4. Distribution of $\mathrm{Pb}$ in at walrus tooth of a 30 year old animal. Operating conditions: ICP-MS: power $1000 \mathrm{~W}$, nebulizer gals llow 1.0 $1 / \mathrm{min}$, dwell time $20 \mathrm{~ms}$; Laser: Q-Switch Mode, flash lamp energy $70 \mathrm{mJJ}$, Q-Switch delay $300 \mu \mathrm{s}$, laser repelition rate $2 \mathrm{H}-\mathrm{z}$, spot size diameter approximately $200 \mu \mathrm{m}, 23$ pulses

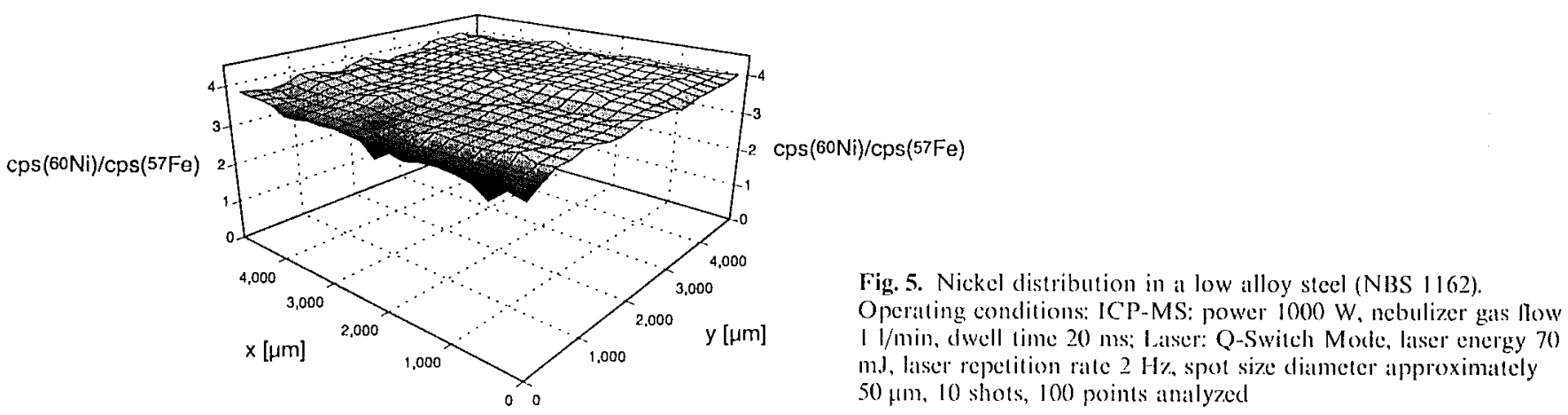


deviation (RSD) of all 100 points for the ratio $\operatorname{cps}\left({ }^{60} \mathrm{Ni}\right)$ $\operatorname{cps}\left({ }^{57} \mathrm{Fe}\right)$ is $4.7 \%$. Nb is added to stecl together with $\mathrm{Ti}$ and/or $V$ to bind carbon as metal-carbide. These compounds are not soluble in iron and they form discrete metal-carbide crystals. Consequently, these elements are distributed inhomogeneously as can be seen in Fig. 6 for $\mathrm{Nb}$ with a RSD of $98 \%$ for the ratio $\operatorname{cps}\left({ }^{93} \mathrm{Nb}\right) / \mathrm{cps}\left({ }^{57} \mathrm{Fe}\right)$.

\section{Electrolhermal vaporization ICP-MS}

Among the advantages of an ETV as a sample introduction technique for ICP-MS are the high transport efficiency compared to conventional solution nebulization and the lower partial pressure of oxygen in the plasma, which consequently lowers the $\mathrm{MO}^{+} / \mathrm{M}^{+}$ratio. Additional benefits occur because the ETV is part of a tandem source; applications which are very different from the GF-AAS type of analysis are possible. The sample only has to be vaporized not atomized and therefore separation of species on the basis of their volatility is possible [11]. The transport efficiency can be further increased in the presence of a matrix element. It has been shown that better sensitivity and reproducibility of ETV-ICP-MS measurements can be achieved by adding compounds such as $\mathrm{NaCl}$ or $\mathrm{PdNO}_{3}$ as matrix modifiers [12]. The matrix modifiers act as carriers for the vaporized analyte elements preventing them from condensing in the transfer lines between the ETV and the ICP. However there is an optimum amount of matrix modifier which should not be exceeded because then signal depression due to the matrix effects and spectral interferences due to molecular ions formed by the matrix modifier both occur [13]. Matrix matched standards must be used to ensure that these two eflects have the same magnitude for standards and samples if an external calibration is to be used for quantitative analysis. Since this can not always be guaranteed, calibration by standard addition is preferable in cases such as the determination of mercury in $\mathrm{AgNO}_{3}$. The $\mathrm{Hg}$ concentration in $\mathrm{AgNO}_{3}$, for photographic purposes, has to be below $0.1 \mu \mathrm{gg} / \mathrm{g}$; this means that the detection limit of the analytical procedure should be better than $0.02 \mu \mathrm{g} / \mathrm{g}$. Analysis of $\mathrm{AgNO}_{3}$ solutions either directly or by fow injection is not sensitive enough especially if one considers the severe memory effects associated with $\mathrm{Hg}$ and the dilution factor of 100 to 1000 involved. The cold vapour technique is also not applicable because of the formation of an amalgam during the reduction step. ETV-ICP-MS can solve the analytical problem using the temperature program given in Table 2. Selective vaporization of the $\mathrm{Hg}$ was used becaluse of the matrix effects induced by the large excess of $\mathrm{Ag}$. $\mathrm{Hg}$ can be vaporized at $800^{\circ} \mathrm{C}$, a temperature where almost no $\mathrm{Ag}$ is vaporized as can be seen from Fig. 7. If a vaporization temperature of $1200^{\circ} \mathrm{C}$ is selected, the sensitivity of the $\mathrm{Hg}$ signal (peak area) is decreased by $25 \%$. Obviously it is very difficult to get matrix matched standards for such a case and therefore standard addition calibration was used. A detection limit of $0.01 \mathrm{\mu g} / \mathrm{g}$ of solid $\mathrm{AgNO}_{3}$ was achieved by analyzing $1 \% \mathrm{AgNO}_{3}(\mathrm{~g} / \mathrm{l} 00 \mathrm{ml})$ solutions.

Thermal vaporization can be found in nature on a large scale in the form of magma degasing which can be considered as the big brother of ETV. Large amounts of

Table 2. ElV Temperature program for the determination of $\mathrm{Hg}$ in $\mathrm{AgNO}_{3}$

\begin{tabular}{rrll}
\hline $\begin{array}{l}\text { Temperature } \\
{\left[\mathrm{C}^{\circ}\right]}\end{array}$ & $\begin{array}{l}\text { Ramp } \\
{[\mathrm{s}]}\end{array}$ & $\begin{array}{l}\text { Hold } \\
{[\mathrm{s}]}\end{array}$ & $\begin{array}{l}\text { Vaporized } \\
\text { species }\end{array}$ \\
\hline 90 & 5 & 5 & \\
110 & 20 & 1 & $\mathrm{H}_{2} \mathrm{O}$ \\
800 & 0 & 2 & $\mathrm{Hg}$ \\
2650 & 1 & 2 & $\mathrm{Ag}$ \\
20 & 1 & 10 & \\
\hline
\end{tabular}

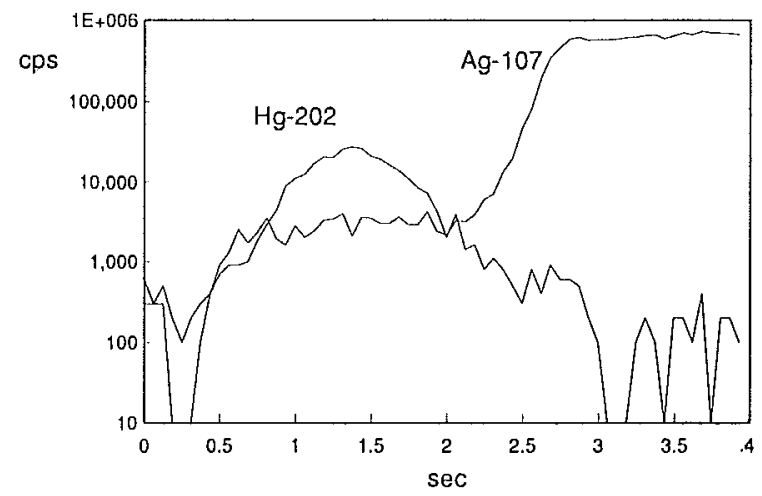

Fig. 7. ETV-lCP-MS signal for $10 \mathrm{ng} / \mathrm{ml} \mathrm{Hg}$ in a $1 \%(\mathrm{~g} / 100 \mathrm{ml}) \mathrm{AgNO}_{3}$ solution. $10 \mu$ solution injected, ${ }^{107} \mathrm{Ag}$ was measured with reduced sensitivity. Operating conditions: ICP-MS: power $1000 \mathrm{~W}$, nebulizer gas llow $0.8 \mathrm{1} / \mathrm{min}$, dwell time $10 \mathrm{~ms}$; ETV (sec Table 2)

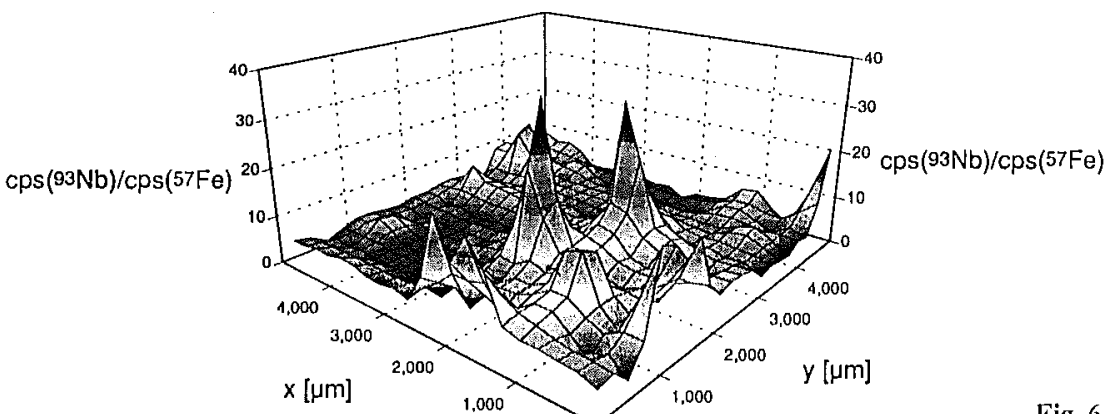

Fig. 6. Niobium distribution in a low alloy steel (NBS 1162). Operating conditions as in Fig. 5 


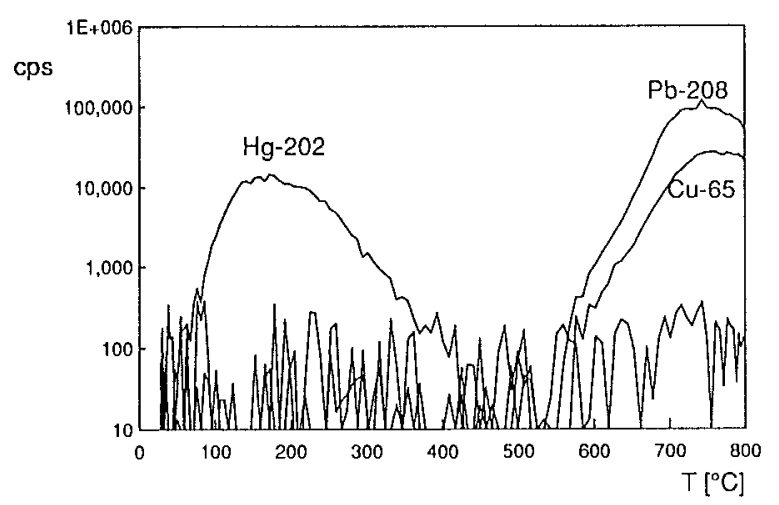

Fig. 8. Evaporation of trace metals from a basaltic lava (Fujiyama, Japan). Operating conditions: power $1200 \mathrm{~W}$, nebulizer gas llow $1 \mathrm{l} / \mathrm{min}$, dwell time $20 \mathrm{~ms}$

gases are released from silicate melts (magmas) during the eruption of volcanoes such as Mount St. Helens in 1980 or Pinatubo in 1992. It is believed that heavy metals are emitted in the form of clusters containing only a few molecules, mostly chlorides and lluorides; these are very volatile at temperatures between $700^{\circ} \mathrm{C}$ and $1200^{\circ} \mathrm{C}$ compared to the oxides or carbonates of these elements $[14,15]$. Parts of these compounds can still be found as inclusions in crystallized minerals and the glassy, ground mass of lava, bombs and ashes. In order to determine these included gases and aerosols and to simulate the conditions in a volcano, the volcanic material was ground to a mean particle diameter of approximately $500 \mu \mathrm{m}$ and then analyzed by ETV-ICP-MS. This was carried out by placing 50 to $100 \mathrm{mg}$ of lava into a graphite boal which was positioned in the middle of the graphite tube. The temperature was then raised to $1000^{\circ} \mathrm{C}$ over $5 \mathrm{~min}$ and 20 elements were analyzed during this process. The temperature in the sample is considerably lower than the nominal temperature set by the software because it is eooled by the carrier gas flowing at $1 \mathrm{l} / \mathrm{min}$ through the furnace. Temperature differences of roughly $200^{\circ} \mathrm{C}$ from a nominal temperature of $1000^{\circ} \mathrm{C}$ have been measured. Figure 8 shows the signals recorded for a basaltic sample from Fujiyama (Japan) for the elements $\mathrm{Cu}, \mathrm{Hg}$ and $\mathrm{Pb}$ with corrected temperatures. The peak maximum for $\mathrm{Hg}$ is already reached at $200^{\circ} \mathrm{C}$; this is not surprising although the maxima of $770^{\circ} \mathrm{C}$ for $\mathrm{Cu}, \mathrm{Pb}$ and a number of other elements is surprisingly low. Emission is only observed during the first healing cycle. These are temperatures which are common in volcanoes and therefore it might be expected that this is an important source for the emission of heavy metals into the environment. Further investigations are planned in order to identify the molecular composition of the volatile species by coupling the ETV directly to a mass spectrometer.

\section{Conclusions}

Laser ablation and electrothermal vaporization are two sample introduction technicues for ICP-MS which help to solve unique analytical problems which could not be solved using only conventional solution nebulization. Both form, together with the ICP, a tandem source for mass spectrometry. Additional information about the sample can be gained because of the possibility of introducing only part of the sample into the ICP depending either on its location in the solid sample $(L \Lambda)$ or its volatility (ETV).

LA can be used for quantitative analysis if matrix matched standards are available but for this type of application the method has to be compared to other well established instrumental methods such as X-ray fluoreseence (XRF) which alre clearly superior when it comes to precision and automation. The advantages of LA-ICPMS compared to XRF are better detection limits, simpler spectra and higher sensitivity for the light elements but the application of the method is often hampered by the absence of suitable standard reference materials. On the other hand, very good results can be achieved in the semiquantitative mode. The full potential of the method can be used for the determination of distribution patterns in solid samples with a high lateral resolution as has been shown for trace elements in hard biological structures or for the homogeneity testing of solid industrial materials. The method compares favombly with other techniques, such as electron microprobe, becaluse of its low detection limits, the wide range of elements from Li to $U$ measurable and independence from the electric conductivity of the sample. Further improvements in terms of spatial resolution and especially in producing quantitative results can be expected.

The applications of ETV-ICP-MS can be separated in two groups: (i) analysis of very small sample volumes and the determination of elements such as $\mathrm{Fc}$ with which oxygen containing molecular ions interfere and (ii) the determination of volatile parts of a sample using an appropriate temperature program which separates on-line these compounds from the refractory parts. (i) is very similar to the well established GF-AAS technique but (ii) makes full use of the tandem source concept and therelore gives new insights into the nature of the samples analyzed. A typical example is the determination of volatile compounds in volcanic eruption products.

Acknowledgment. The authors thank Tom Northcote for providing the sturgeon sample

\section{References}

1. Moenke-Blankenburg L (1989) Laser microanalysis. Wiley, New York Chichester Brisbane Toronto Singalpore

2. Darke SA, Tyson JF (1993) J Anal At Spectrom 8:145-209

3. Chenery S, Cook JM (1993) J Anal At Spectrom 8:299-303

4. Fuge R, Pilmer TJ, Pearce NJG, Perkins WT (1993) Appl Geochem [Suppl] 2:111-116

5. Etoh T, Yamada M, Matsubara M (1991) Anal Sci $7: 1263-1264$

6. Richner P, Evans D (1993) At Spectroscopy 14:157-161

7. Hieftje GM, Norman LA (1992) Int J Mass Spectrom lon Process 118/119:519-573

8. Cousin H, Magyar B (1994) Mikrochim Acta (in press)

9. Denoyer E (1992) I Anal At Spectrom 7:1187-1193 
10. Wagemann R, Stewart REA, Beland P, Desjardins C (1990) Can Bull Fish Aquatic Sci 224: 191-206

11. Richner P, Wunderli S (1993) J Anal At Spectrom $8: 45-49$

12. Ediger RD, Beres SA (1992) Spectrochim Acta 47B : 907--922
13. Grégoire DC, Sturgeon RE (1993) Spectrochim Acta $48 B: 1347-1364$

14. Symons RB, Rose WI, Gerlach TM, Briggs PH, Halmon RS (1990) Bull Volcanol 52:355-374

15. Amman $M$, Burtscher H (1990) Bull Volcanol 52:577-583 